\title{
Renal Association Clinical Practice Guideline on Planning, Initiating and Withdrawal of Renal Replacement Therapy
}

\author{
Professor Ken Farrington $^{\mathrm{a}}$ and Dr Graham Warwick ${ }^{\mathrm{b}}$ \\ ${ }^{a}$ Consultant Nephrologist, Lister Hospital, East and North Hertfordshire NHS Trust \\ ${ }^{b}$ Consultant Nephrologist, Renal and Urology Directorate, University Hospital Leicester
}

\section{Key Words}

Planning for renal replacement therapy - patient education . haemodialysis · peritoneal dialysis - transplantation - end of life care

\section{Introduction}

This guideline provides recommendations on best practice in the planning, initiating and withdrawal of renal replacement therapy. The guideline links with many of the objectives relating to renal replacement therapy described within the National Service Framework for Renal Services Part 1 [1]. This NSF document highlighted the need for renal units to deliver individualised patient education to allow patients to make an informed choice of treatment modality, timely preparation for renal replacement therapy and empowerment of the patient from the start to the end of their treatment pathway.

In the preparation of this guideline the authors performed a systematic search of the literature on planning and initiating of renal replacement therapy and end of life care which was published in English up to February 2009. The evidence for these recommendations has been assessed using the modified GRADE system. The modified GRADE system defines both the strength of the recommendations of the guideline authors and the level of evidence upon which each of the recommendations is based. This grading system classifies expert recommendations as 'strong' (Grade 1) or 'weak' (Grade 2) based upon the balance between the benefits and risks, burden and cost. The quality or level of evidence is designated as high (Grade A), moderate (Grade B), low (Grade C) or very low (D) depending on factors such as study design, directness of evidence
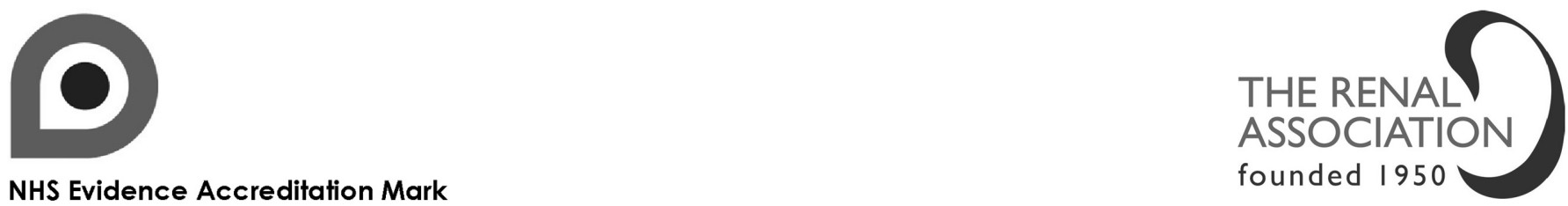

NHS Evidence Accreditation Mark

C 2011 S. Karger AG, Basel

$1160-2110 / 11 / 1185-000189 \$ 38.00 / 0$
Email: ken.farrington@nhs.net and graham.warwick@uhl-tr.nhs.uk 
and consistency of results. Grades of recommendation and quality of evidence may range from $1 \mathrm{~A}$ to $2 \mathrm{D}$. The GRADE system has been developed to maximise the usefulness of clinical practice guidelines in the management of typical patients.

This guideline has been harmonised with other guideline groups [2-4] whenever possible. The recommendations have been reviewed by patient representatives as well as key stakeholders within the multidisciplinary team caring for patients with established renal failure. The preparation of this guideline has identified that there is great need for high quality clinical research and audit in many aspects of the planning, initiation and withdrawal of renal replacement therapy.

\section{References}

1 Department of Health. The National Service Framework for Renal Services Part 1. Dialysis and Transplantation. 2004

2 European Best Practice Guidelines. The initiation of dialysis. Nephrol Dial Transplant 2005;20(Suppl 9):ix3-ix7

3 Department of Health. End of Life Strategy. 2008

4 DH Renal NSF team and Marie Curie Palliative Care Institute. Guidelines for Liverpool Care Pathway prescribing in advanced kidney disease. 2008 


\section{Summary of Clinical Practice Guidelines}

\section{Planning, Initiating and Withdrawal of RRT}

(Guidelines 1.1-1.2)

\section{Guideline 1.1 - RRT: Timely nephrology referral}

We recommend that most patients with CKD stage 4-5 (eGFR $\left.<30 \mathrm{ml} / \mathrm{min} / 1.73 \mathrm{~m}^{2}\right)$ or with CKD stage 3 and rapidly deteriorating renal function should be referred for assessment by a nephrologist. (1B)

\section{Guideline 1.2 - RRT: Timely nephrology referral}

We suggest that patients should be referred at least a year before they might be anticipated to require renal replacement therapy (RRT). (2B)

\section{Planning, Initiating and Withdrawal of RRT}

(Guidelines 2.1-2.3)

\section{Guideline 2.1 - RRT: Nephrology follow-up}

We recommend that most patients whose eGFR is $<30 \mathrm{ml} / \mathrm{min} / 1.73 \mathrm{~m}^{2}$ and declining should be under the care of a nephrologist. (1B)

\section{Guideline 2.2 - RRT: Nephrology follow-up}

We recommend that these patients should be managed in a dedicated clinic by a multidisciplinary team. (1B)

\section{Guideline 2.3 - RRT: Nephrology follow-up}

We suggest the frequency of nephrology follow-up should be intensified when the eGFR has fallen to $<15 \mathrm{ml} / \mathrm{min} / 1.73 \mathrm{~m}^{2}$ if dialysis treatment is not started. (2D)

\section{Planning, Initiating and Withdrawal of RRT}

(Guidelines 3.1-3.6)

\section{Guideline 3.1 - RRT: Preparing patients for RRT}

We recommend that most patients whose eGFR is $<30 \mathrm{ml} / \mathrm{min} / 1.73 \mathrm{~m}^{2}$ and declining should receive timely and personalised information regarding established kidney failure and renal replacement therapy options so they can make an informed decision about treatment. (1B)

\section{Guideline 3.2 - RRT: Preparing patients for RRT}

We recommend that patients who present with advanced kidney failure and are likely to need RRT within 3 months should be able to access an accelerated care pathway to deliver education, information and prepare for RRT. (1D)

Guideline 3.3 - RRT: Preparing patients for RRT

We recommend that all medically suitable patients should be informed about the advantages of pre-emptive living kidney transplantation and efforts made to identify a potential donor to allow pre-emptive transplantation before the need for renal replacement therapy. (1B)

\section{Guideline 3.4-RRT: Preparing patients for RRT}

We recommend that all suitable patients should be listed for cadaveric transplantation six months before the anticipated start of renal replacement therapy. (1B)

\section{Guideline 3.5 - RRT: Preparing patients for RRT}

We suggest that all patients should be encouraged to perform home dialysis therapy where possible, as part of an integrated approach to renal replacement therapy. (2B)

\section{Guideline 3.6 - RRT: Preparing patients for RRT}

We suggest that, where home dialysis is not possible, patients and their carers/partners should be actively involved in their dialysis treatment, be encouraged to perform as much self-care as possible and be engaged in all aspects of their treatment including medicines management and changes in diet and lifestyle. (2B)

\section{Planning, Initiating and Withdrawal of RRT (Guidelines 4.1-4.3)}

\section{Guideline 4.1 - RRT: Educating patients and carers for $R R T$}

We recommend that all patients with severe CKD (stage 5 and progressive stage 4), together with their families and carers, should be offered an appropriate education programme aimed at improving their knowledge and understanding of their condition, and of the options for treatment. (1B)

\section{Guideline 4.2 - RRT: Educating patients and carers for $R R T$}

We suggest that education programmes should be multidisciplinary, multifaceted, tailored to the needs of the individual, and based on the principles of adult learning. A variety of approaches should be available including individual conversations, group work, written materials, DVD/CDs, access to expert patients. There 
should be opportunities for informal follow up. The information imparted should be relevant to the person, with the method, scale, pace and scope of the delivery being suited to the individual's learning style, capacity and preferences. The programme should also include provision for the education of patients who present late, and initiate dialysis in an unplanned fashion. (2C)

\section{Guideline 4.3 - RRT: Educating patients and carers for $R R T$}

We suggest that pre-renal replacement therapy education programmes for patients and their families and carers should be continued into the treatment phase, with the aims of optimising patient involvement in their own care, improving treatment adherence, and fostering good communication and collaborative relationships with caregivers. (2C)

\section{Planning, Initiating and Withdrawal of RRT} (Guidelines 5.1-5.6)

\section{Guideline 5.1 - RRT: Initiating RRT}

We recommend that patients known to nephrology services for 3 months or more and who are planned to have renal support should start renal replacement therapy in a controlled manner, without the need for hospital admission and using an established access (arteriovenous fistula $[\mathrm{AVF}]$, arteriovenous $[\mathrm{AV}] \mathrm{graft}$, $\mathrm{PD}$ catheter) or by pre-emptive renal transplantation. (1B)

\section{Guideline 5.2 - RRT: Initiating RRT}

We recommend that the decision to start RRT in patients with CKD stage $5\left(\mathrm{eGFR}<15 \mathrm{ml} / \mathrm{min} / 1.73 \mathrm{~m}^{2}\right)$ should be based on a careful discussion with the patient of the risks and benefits of RRT taking into account the patient's symptoms and signs of renal failure, nutritional status, co-morbidity, functional status, and the physical, psychological and social consequences of starting dialysis in that individual. (1D)

\section{Guideline 5.3 - RRT: Initiating RRT}

We suggest that serious consideration should be given to starting renal replacement therapy in patients with an eGFR $<6 \mathrm{ml} / \mathrm{min} / 1.73 \mathrm{~m}^{2}$, even if the patient is asymptomatic. $(2 \mathrm{C})$

\section{Guideline 5.4 - RRT: Initiating RRT}

We recommend that once a decision has been made to start dialysis in a patient with established access there should be no delay in starting treatment i.e. no waiting list to start dialysis. (1D)

\section{Guideline 5.5 - RRT: Initiating RRT}

We recommend that urgent dialysis via a haemodialysis catheter should only be initiated where there is a clear clinical indication. (1D)

\section{Guideline 5.6 - RRT: Initiating RRT}

We suggest that where dialysis is started via an established access (vascular or peritoneal) which fails to work effectively urgent corrective action should be taken and dialysis via a haemodialysis catheter avoided if possible. (2D)

\section{Planning, Initiating and Withdrawal of RRT (Guidelines 6.1-6.5)}

\section{Guideline 6.1 - RRT: End of life care: Conservative kidney management and withdrawal from dialysis}

Conservative kidney care:

We recommend that patients with advanced kidney disease (CKD Stage 4 and 5) who, having opted not to dialyse, are undergoing conservative kidney management and those patients who have imminent or immediate end-of-life care needs should be identified and their care prioritised. (1C)

\section{Guideline 6.2 - RRT: End of life care: Conservative kidney management and withdrawal from dialysis}

Patients who are deteriorating despite dialysis:

We recommend that patients who are struggling to cope on long-term dialysis as a result of progressive deterioration of underlying, irreversible, clinical problems, or sudden onset of a catastrophic clinical event, such as a stroke, should be recognised as being in imminent or immediate need of end-of-life care. (1C)

Guideline 6.3 - RRT: End of life care: Conservative kidney management and withdrawal from dialysis

\section{Advance care planning:}

We recommend that patients with a recognised need for end-of-life care, including those patients undergoing 
conservative kidney care and those deteriorating despite dialysis, should have an Advance Care Plan. (1C)

Guideline 6.4 - RRT: End of life care:

Conservative kidney management and withdrawal from dialysis

\section{Dialysis withdrawal:}

We recommend that any decision to discontinue dialysis should be made within the context of ongoing end-of-life care planning. It should be made jointly by the patient and the responsible nephrologist in full consultation with relatives and carers, the family practitioner and members of the caring team. An assessment of competence should be carried out. Depression may need to be formally excluded. (1C)

Guideline 6.5 - RRT: End of life care: Conservative kidney management and withdrawal from dialysis

\section{Care in the last days:}

We recommend that, in the last days of life, there should be good symptom relief, psychological, spiritual and culturally sensitive care for the dying patient and their family (whether at home, in a hospice or a hospital setting), followed by the provision of culturally appropriate bereavement support. (1C) 


\section{Summary of Audit Measures}

1. Percentage of patients commencing RRT referred $<3$ months and $<12$ months before date of starting RRT.

2. Percentage of incident RRT patients followed up for $>3$ months in dedicated pre-dialysis or low clearance clinic.

3. Proportion of incident patients on UK transplant waiting list at RRT initiation.

4. Proportion of incident RRT patients transplanted pre-emptively from living donors and cadaveric donors.

5. Mean eGFR at time of pre-emptive transplantation.

6. Proportion of incidents patients commencing peritoneal or home haemodialysis.

7. Proportion of patients who have undergone a formal education programme prior to initiation of RRT.

8. Proportion of haemodialysis patients who report that they have been offered a choice of RRT modality.

9. Proportion of patients who have initiated dialysis in an unplanned fashion who have undergone formal education by 3 months.

10. Evidence of formal continuing education programme for patients on dialysis.

11. Proportion of incident patients known to nephrology services for 3 months or more prior to initiation (planned initiation).
12. Proportion of planned initiations with established access or pre-emptive transplantation.

13. Inpatient/outpatient status of planned initiations.

14. Mean eGFR at start of renal replacement therapy.

15. Units should have a register of patients with End of Life Care needs, including those patients undergoing conservative kidney management, those deteriorating despite dialysis, and those withdrawing from dialysis. The register should link with primary care End of Life Registers.

16. The number of patients with Stage 5 CKD who are undergoing conservative kidney management as a proportion of all patients with Stage 5 CKD.

17. The number of patients withdrawing from dialysis as a proportion of all deaths on dialysis.

18. The proportion of those patients identified as having End of Life Care needs who have a workable Advance Care Plan, which includes details of the nominated renal Key-Worker, patient preferences and choices with respect to priorities of care, and details of the individual needs of carers.

19. The proportion of all expected in-patient deaths in which the Integrated (Liverpool) Care Pathway for care of the dying has been utilised.

20. Units should participate in National End of Life Care audits such as the Integrated (Liverpool) Care Pathway: National care of the dying audit - hospitals. 


\section{Full Clinical Practice Guidelines}

\section{Planning, Initiating and Withdrawal of RRT (Guidelines 1.1-1.2)}

\section{Guideline 1.1 - RRT: Timely nephrology referral}

We recommend that most patients with CKD stage 4-5 (eGFR $\left.<30 \mathrm{ml} / \mathrm{min} / 1.73 \mathrm{~m}^{2}\right)$ or with CKD stage 3 and rapidly deteriorating renal function should be referred for assessment by a nephrologist. (1B)

\section{Guideline 1.2 - RRT: Timely nephrology referral}

We suggest that patients should be referred at least a year before they might be anticipated to require renal replacement therapy (RRT). (2B)

\section{Audit measure 1}

Percentage of patients commencing RRT referred $<3$ months and $<12$ months before date of starting RRT

\section{Rationale for 1.1-1.2}

The routine reporting of estimated glomerular filtration rate (eGFR) by chemical pathology laboratories helps to identify patients with significant chronic kidney disease (CKD) and may help to promote timely referral to a nephrologist. Over more than 25 years, retrospective and case control studies have demonstrated consistently the detrimental effects of late nephrological referral. These include lack of adequate intervention to delay the progression of renal failure, higher morbidity and mortality, poorer quality of life on dialysis, missed opportunities to have pre-emptive renal transplantation and, for some patients, inappropriate dialysis treatment where conservative care might have been chosen by an informed patient [1-4]. However, the 2008 UK NICE guidance on chronic kidney disease found no evidence to guide the optimum timing of referral of patients with CKD [5]. The guideline group did recommend the referral of all patients with CKD stage $4-5$ or patients with rapidly deteriorating renal function (defined as a reduction in eGFR of $>5 \mathrm{ml} / \mathrm{min} / 1.73 \mathrm{~m}^{2}$ per year or $>10 \mathrm{ml} / \mathrm{min} / 1.73 \mathrm{~m}^{2}$ per 5 years). There may be patients with CKD stage $4-5$ who do not require referral because of severe co-morbidity, very poor quality of life or limited life expectancy from other conditions; where there is doubt a discussion between patient/carer, referrer and nephrologist may help to clarify this.

Timely referral provides the opportunity to plan for renal replacement therapy (RRT) or conservative kidney care. Patients who have been under the care of nephrology services for more than 1 month are more likely to initiate haemodialysis (HD) using an AVF [6]. A retrospective analysis of 109,321 incident HD patients in the USA found that, compared to patients with at least 3 months of predialysis care, the relative risk of death of patients for patients with one or two months pre-dialysis nephrology care was 1.23 whilst that for patients with no predialysis nephrology care was 1.51 [4]. Now that most patients with advanced kidney failure, regardless of age and co-morbidity, are considered as potential candidates for RRT, the question of whether or not such treatment is the most appropriate option for the individual patient, has assumed increasing importance. Until recently, acceptance or non-acceptance for RRT in the UK was often determined by whether or not a patient was referred to a nephrology service. Effectively, decisions not to initiate RRT were taken by family members or referring physicians in isolation rather than in conjunction with the multidisciplinary nephrology team [7]. It is often difficult to decide if patients with major co-morbidity will or will not benefit from starting dialysis, even if referred well in advance of the need for RRT, and there have been few studies of the decision not to start dialysis [8]. Appropriate decision making may be facilitated by referral of all patients with advanced renal failure (eGFR $<30 \mathrm{ml} / \mathrm{min}$ ) and a predicted life expectancy of more than 6 months to a nephrology services for consideration of RRT.

Although the principle of early referral to allow preparation for RRT is well accepted, this is not always easy to achieve in clinical practice. The majority of patients with CKD stage 4 will not progress to established kidney failure and at present there are relatively poor methods for predicting those who will progress [9]. Furthermore, the rate of decline in eGFR may be difficult to predict even with serial measurements and extrapolation of eGFR v. time plots as some patients remain stable over many years. Finally, the optimal time to allow adequate preparation is not clear. Many studies have used 3 or 4 months to define late referral but in practice it may take more than a year to prepare fully for renal replacement therapy [10]. 


\section{References}

1 Ratcliffe PJ, Phillips RE, Oliver DO. Late referral for maintenance dialysis. Br Med J 1984;288:441-443

$\checkmark 2$ Roderick P, Jones C, Tomson C and Mason J. Late referral for dialysis: Improving the management of chronic kidney disease. Q J Med 2002:95:363-370

-3 Stack, AG. Impact of timing of nephrology referral and pre-ESRD care on mortality risk among new ESRD patients in the United States. Am J Kidney Dis 2003; 41:310-318

4 Khan SS, Xue JL, Kazmi WH, et al. Does predialysis nephrology care influence patient survival after initiation of dialysis? Kidney Int 2005; 67:1038-1046

5 National Collaborating Centre for Chronic Conditions. Chronic kidney disease: national clinical guideline for early identification and management in adults in primary and secondary care. London: Royal College of Physicians, September 2008
6 Rayner HC, Besarab A, Brown WW, et al. Vascular access results from the Dialysis Outcomes and Practice Patterns Study (DOPPS): performance against Kidney Disease Outcomes Quality Initiative (K/DOQI) Clinical Practice Guidelines. Am J Kidney Dis 2004;44(Suppl 3):22-26

7 Challah S, Wing AJ, Bauer R, et al. Negative selection of patients for dialysis in the United Kingdom. Br Med J 1984; 288:1119-1122

8 Hirsch DJ, West ML, Cohen AD, et al. Experience with not offering dialysis to patients with a poor prognosis. Am J Kidney Dis 1994;23: 463-466

9 Taal MW, Brenner BM. Predicting initiation and progression of chronic kidney disease: Developing renal risk scores. Kidney Int 2006;70:16941705

10 Buck J, Baker R, Cannaby A-M, et al. Why do patients known to renal services still undergo urgent dialysis initiation? A cross-sectional survey. Nephrol Dial Transplant 2007;22:3240-3245 


\section{Planning, Initiating and Withdrawal of RRT}

(Guidelines 2.1-2.3)

\section{Guideline 2.1 - RRT: Nephrology follow-up}

We recommend that most patients whose eGFR is $<30 \mathrm{ml} / \mathrm{min} / 1.73 \mathrm{~m}^{2}$ and declining should be under the care of a nephrologist. (1B)

\section{Guideline 2.2 - RRT: Nephrology follow-up}

We recommend that these patients should be managed in a dedicated clinic by a multidisciplinary team. (1B)

\section{Guideline 2.3 - RRT: Nephrology follow-up}

We suggest the frequency of nephrology follow-up should be intensified when the eGFR has fallen to $<15 \mathrm{ml} / \mathrm{min} / 1.73 \mathrm{~m}^{2}$ if dialysis treatment is not started. (2D)

\section{Audit measure 2}

Percentage of incident RRT patients followed up for $>3$ months in dedicated pre-dialysis or low clearance clinic

\section{Rationale for 2.1-2.3}

There have been no randomised controlled trials or meta-analyses specifically looking at the influence of frequency of follow-up on outcomes in patients approaching the need for renal replacement therapy [1]. However, regular clinical reviews are recommended by most guidelines as there is evidence that progression of renal failure may be prevented or slowed significantly by strict blood pressure control, strict glycaemic control in patients with diabetes mellitus, the use of certain drugs (such as angiotensin converting enzyme inhibitors and angiotensin receptor blockers in patients with proteinuria), and possibly revascularisation procedures in selected patients with renovascular disease $[1,2]$.

Patients with eGFR of $<30 \mathrm{ml} / \mathrm{min}$ or less should undergo clinical review at least every 3 months which should include measurement of eGFR, haemoglobin, calcium, phosphate, potassium, bicarbonate and parathyroid hormone and dietary assessment [1].

The European Best Practice Guidelines recommend that patients should be followed-up monthly once the eGFR has fallen to $<15 \mathrm{ml} / \mathrm{min} / 1.73 \mathrm{~m}^{2}$ [3]. There is no sound evidence base for this recommendation and it may not be necessary for many patients. However, as renal function declines, many patients will require more frequent review, often by the multidisciplinary team to deal with complications of renal failure (anaemia, acidosis, bone disease, nutrition) and to ensure the optimal timing of starting dialysis or pre-emptive transplantation (see section 3 ).

There are many studies albeit of variable quality and generally of small numbers, which have shown that a dedicated pre-dialysis (or 'low clearance') clinic is associated with improved outcomes and reduced urgent initiation of dialysis (4-7). Such clinics exist in many nephrology departments in the UK but there is a lack of consensus on a name for such a clinic. Pre-dialysis implies all patients will receive dialysis when some patients will be transplanted and others will receive conservative kidney care. The frequently used alternative, 'low clearance', may not be very meaningful to patients.

The precise make up and organisation of these clinics will vary according to local expertise, facilities and resources and there is insufficient evidence to recommend a particular model or staffing structure.

\section{References}

1 National Collaborating Centre for Chronic Conditions. Chronic kidney disease: national clinical guideline for early identification and management in adults in primary and secondary care. London: Royal College of Physicians, September 2008

2 Thomas MC. Regular and frequent follow-up of patients with pre-endstage kidney disease Nephrology 2007;12:S44-45

3 European Best Practice Guidelines. The initiation of dialysis. Nephrol Dial Transplant 2005; 20 [Suppl 9]: ix3-ix7

4 Levin A, Lewis $\mathrm{M}$, et al. Multidisciplinary predialysis programs: quantification and limitations of their impact on patient outcomes in two Canadian settings. Am J Kidney Dis 1997;29:533-540
Ravani P, Marinangeli G, Stacchiotti L, et al. Structured pre-dialysis programs: More than just timely referral? J Nephrology 2003;16:862-869

6 Ravani P, Marinangeli G, Tancredi M, et al. Multidisciplinary chronic disease management improves survival on dialysis. J Nephrology 2003; 16:870-877

7 Buck J, Baker R, Cannaby A-M, et al. Why do patients known to renal services still undergo urgent dialysis initiation? A cross-sectional survey. Nephrol Dial Transplant 2007;22:3240-3245 


\section{Planning, Initiating and Withdrawal of RRT}

(Guidelines 3.1-3.6)

\section{Guideline 3.1 - RRT: Preparing for renal replacement therapy}

We recommend that most patients whose eGFR is $<30 \mathrm{ml} / \mathrm{min} / 1.73 \mathrm{~m}^{2}$ and declining should receive timely and personalised information regarding established kidney failure and renal replacement therapy options so they can make an informed decision about treatment. (1B)

\section{Guideline 3.2 - RRT: Preparing for renal replacement therapy}

We recommend that patients who present with advanced kidney failure and are likely to need RRT within 3 months should be able to access an accelerated care pathway to deliver education, information and prepare for RRT. (1D).

\section{Guideline 3.3 - RRT: Preparing for renal replacement therapy}

We recommend that all medically suitable patients should be informed about the advantages of preemptive living kidney transplantation and efforts made to identify a potential donor to allow pre-emptive transplantation the need for renal replacement therapy. (1B)

\section{Guideline 3.4 - RRT: Preparing for renal replacement therapy}

We recommend that all suitable patients should be listed for cadaveric transplantation six months before the anticipated start of renal replacement therapy. (1B)

\section{Guideline 3.5 - RRT: Preparing for renal replacement therapy}

We suggest that all patients should be encouraged to perform home dialysis therapy where possible, as part of an integrated approach to renal replacement therapy. (2B)

\section{Guideline 3.6 - RRT: Preparing for renal replacement therapy}

We suggest that where home dialysis is not possible, patients and their carers/partners should be actively involved in their dialysis treatment, be encouraged to perform as much self-care as possible and be engaged in all aspects of their treatment including medicines management and changes in diet and lifestyle. (2B)
Audit measures 3-6

Proportion of incident patients on UK transplant waiting list at RRT initiation

Proportion of incident RRT patients transplanted pre-emptively from living donors and cadaveric donors

Mean eGFR at time of pre-emptive transplantation

Proportion of incidents patients commencing peritoneal or home haemodialysis

\section{Rationale for 3.1-3.6}

The 2004 National Service Framework Part 1 emphasises the importance of patient choice and of the need for education in the phase leading up to dialysis, transplantation or conservative care for advanced CKD [1]. An important concept to convey to patients is that the different treatment options should be seen as an integrated package where patients may move from one treatment to another over their 'career' of renal replacement therapy [2]. There is good evidence this information should be available to patients through a structured education programme which has been shown to have a number of benefits (see section 4). Where patients present with advanced kidney failure and are likely to need RRT in less than three months, this programme should be delivered in an accelerated format.

An important part of the preparation for renal replacement therapy should include planning for pre-emptive transplantation. There is a consensus that pre-emptive transplantation (i.e. before patients are established on dialysis) is associated with improved graft and patient survival (3-5). This is based mainly on large retrospective registry data or case control series; there is no randomised controlled trial. Although there may be issues relating to differences in recipient characteristics, quality of tissue type matching and of donor kidney, the data supports generally a strategy to provide pre-emptive transplantation. However, a short period on dialysis ( $<6$ months) may have no influence on outcomes [6]. The UK transplant guidelines recommend listing patients for renal transplantation who are predicted to start dialysis within six months [7] although this is not easy to predict accurately. Where there is a living related donor, the process of donor assessment and work-up should be pursued in a timely manner to allow transplantation to be carried out pre-emptively. However, the optimal time and level of eGFR at which pre-emptive transplantation should be carried out is not clear and there may be a possibility of performing this too early [8].

Although transplantation is shown to have the best outcomes, this may not be possible for many patients due to co-morbidity, lack of a donor or, sometimes, 
patient choice. There are no adequate randomised controlled trials comparing outcomes of peritoneal dialysis (PD) versus haemodialysis (HD) or of home versus centre based therapies but there is considerable observational data which suggests that patients performing home therapies have improved survival and improved quality of life $[9,10]$. These data are difficult to interpret because patients choosing self-care are often younger and fitter with fewer co-morbidities but this advantage seems to persist when corrected for these factors $[9,11]$.

The UK National Institute for Clinical Excellence commissioned a systematic review of home haemodialysis versus hospital or satellite based dialysis which despite the lack of grade 1 evidence concluded that home HD offered advantages to patients in terms of quality of life, flexibility, reduced travel, improved survival and was cost effective to the NHS [12].

Peritoneal dialysis remains an important modality of renal replacement in the United Kingdom accounting for $10.7 \%$ of prevalent patients in the 2007 UK Renal Registry report [13]. There are no convincing data that patient survival on peritoneal dialysis is worse than haemodialysis although the technique failure rate is high at three years. However, patients will still often prefer this treatment because of the independence, control and flexibility it offers and there is evidence of better quality of life compared to haemodialysis [14].

Self care is now widely promoted for the management of chronic disease $[15,16]$. Home dialysis therapies (either haemodialysis or peritoneal dialysis) are good examples of complex treatments which patient can be taught to self manage. In contrast, many patients within main centre and satellite haemodialysis units are or become very dependent. In part this relates to co-morbid conditions but even in the early days of dialysis the concept of 'learned helplessness' was described by Blagg and Scribner and is even more relevant today with the increasing age of the RRT population [17]. There has been renewed interest in recent years in improving self-care and self-efficacy amongst patients with chronic kidney disease starting from the time of diagnosis and continuing to patients receiving renal replacement therapy. Many centres in the UK have now established programmes to allow patients to take a greater role in their dialysis treatment even if this is hospital based. However, the evidence that this leads to improved survival or other hard outcomes is limited. Indeed a recent guideline statement on self care for chronic disease management by the National Guideline Clearinghouse on behalf of the US Agency for Healthcare Research and Quality contained minimal reference to renal replacement therapy [18]. This is an area where more research on the benefits of self-care within haemodialysis centres is required.

The rationale and evidence for hepatitis $\mathrm{B}$ vaccination in patients who are predicted to need renal replacement is covered in a separate module in these clinical practice guidelines.

\section{References}

1 Department of Health. The National Service Framework for Renal Services Part 1: Dialysis and Transplantation. 2004

2 Coles GA, Williams JD. What is the place of peritoneal dialysis in the integrated treatment of renal failure? Kidney Int 1998;54:2234-2240

-3 Meier-Kriesche HU, Port FK, Ojo AO, et al. Effect of waiting time on renal transplant outcome. Kidney Int 2000;58:1311-1317

4 Mange KC, Joffe MM, Feldman HI. Effect of the use or non-use of long-term dialysis on the subsequent survival of renal transplants from living donors. N Engl J Med 2001; 344:726-731

5 Gill JS, Tonelli M, Johnson N, Pereira BJ. Why do pre-emptive kidney transplant recipients have an allograft survival advantage? Transplantation 2004;78:873-879

-6 Goldfarb-Rumyantzev A, Hurdle JF, Scandling J, et al. Duration of end-stage renal disease and kidney transplant outcome. Nephrol Dial Transplant 2005;20:167-175

7 http://www.uktransplant.org.uk/ukt/about_transplants/organ_allocation/ kidney_(renal)/national_protocols_and_guidelines/protocols_and_ guidelines/transplant_list_criteria.jsp (accessed 14 Dec 2008)

8 Akkina SK, Connaire JJ, Snyder JJ, et al. Earlier is not necessarily better in pre-emptive kidney transplantation. Am J Transplant 2008;8:20712076

9 Woods JD, Port FK, Stannard D, et al. Comparison of mortality with home haemodialysis and centre haemodialysis: a national study. Kidney Int 1996;49:1464-1470

Planning, Initiating and Withdrawal of Renal Replacement Therapy
10 Evans RW, Manninen DL, Garrison LP, et al. The quality of life of patients with end stage renal disease. N Engl J Med 1985;312:553-559

11 Sanerl E, Nitsch D, Descoeudres C, et al. Outcome of home haemodialysis patients: a case-cohort study. Nephrol Dial Transplant 2005;20:604-610

12 http://www.nice.org.uk/nicemedia/pdf/HvH_Assessment_report.pdf

13 Ansell D, Feehally J, Feest TG, et al. UK Renal Registry Report 2007. UK Renal Registry, Bristol, UK

14 Kutner NG, Zhang R, Barnhart $\mathrm{H}$, et al. Health status and quality of life reported by incident patients after 1 year on haemodialysis or peritoneal dialysis. Nephrol Dial Transplant 2005;20:2159-2167

15 Bodenheimer T, Lorig K, Holman H, et al. Patient self-management of chronic disease in primary care. JAMA. 2002;288:2469-2475

16 Chronic disease management: a compendium of information (available at http://www.natpact.nhs.uk/uploads/Chronic\%20Care\%20 Compendium.pdf accessed 22 Feb 2009)

17 Blagg CR, Scribner BH: Dialysis: Medical, psychological, and economic problems unique to the dialysis patient, in The Kidney. Eds Brenner BM, Rector FC, Philadelphia, WB Saunders, 1976, pp 1705-1744

$18 \mathrm{http} / /$ www.guideline.gov/summary/summary.aspx?ss=15\&doc_id= $10593 \&$ nbr $=5535$ (accessed 22 Feb 2009) 


\section{Planning, Initiating and Withdrawal of RRT (Guidelines 4.1-4.3)}

Guideline 4.1 - RRT: Educating patients and carers for renal replacement therapy

We recommend that all patients with severe CKD (stage 5 and progressive stage 4), together with their families and carers, should be offered an appropriate education programme aimed at improving their knowledge and understanding of their condition, and of the options for treatment. (1B)

\section{Guideline 4.2 - RRT: Educating patients and carers} for renal replacement therapy

We suggest that education programmes should be multidisciplinary, multifaceted, tailored to the needs of the individual, and based on the principles of adult learning. A variety of approaches should be available including individual conversations, group work, written materials, DVD/CDs, access to expert patients. There should be opportunities for informal follow up. The information imparted should be relevant to the person, with the method, scale, pace and scope of the delivery being suited to the individual's learning style, capacity and preferences. The programme should also include provision for the education of patients who present late, and initiate dialysis in an unplanned fashion. (2C)

\section{Guideline 4.3 - RRT: Educating patients and carers for renal replacement therapy}

We suggest that pre-renal replacement therapy education programmes for patients and their families and carers should be continued into the treatment phase, with the aims of optimising patient involvement in their own care, improving treatment adherence, and fostering good communication and collaborative relationships with caregivers. $(2 \mathrm{C})$

\section{Audit measures $7-10$}

Proportion of patients who have undergone a formal education programme prior to initiation of RRT

Proportion of haemodialysis patients who report that they have been offered a choice of RRT modality

Proportion of patients who have initiated dialysis in an unplanned fashion who have undergone formal education by 3 months

Evidence of formal continuing education programme for patients on dialysis

\section{Rationale for 4.1-4.3}

The NHS Constitution [1] enshrines the rights of patients to 'easily accessible, reliable and relevant information to enable you to participate fully in your own healthcare decisions and to support you in making choices'. An adequately resourced pre-dialysis education programme is an essential pre-requisite for patients with progressive chronic kidney disease who need to make choices about renal replacement therapy. The most appropriate setting for this may be as part of a multidisciplinary clinic which integrates clinical expertise, patient education, and comprehensive supportive services $[2,3]$ and which encapsulates the flow from diagnosis, through education, to timely referral for access creation or pre-emptive transplantation. To realise many of the potential benefits, such programmes require support by adequate resources for dialysis provision [3].

Patient education aims to provide information about the functions of the kidneys, their derangements in disease, and about available treatment options for kidney failure and their implications for lifestyle. This knowledge is vital to inform treatment choice decisions. Pre-dialysis educational programmes also aim to promote patient self-management allowing them to take a degree of control over living with a chronic condition, and ideally providing links to expert patient programmes [4].

The available evidence suggests that, as well as improving patient knowledge and understanding [5-7], pre-dialysis education confers many additional advantages. These include an improved sense of well-being, enhanced mood, reduced levels of anxiety, and better physical functioning [8]. Patients who have received pre-dialysis education also have a lower incidence of unplanned initiation onto dialysis [9-11], even excluding late referrals. Furthermore, fewer patients initiate dialysis with haemodialysis catheters [12].

There is also an association between pre-dialysis education and delay in the need for dialysis initiation, often by many months, an effect which has been attributed to improved pre-dialysis management $[5,13,14]$. Another consistent finding is that patients, who as part of pre-dialysis education have received adequate information about available treatment options, were more likely to choose a self-care based therapy as first modality $[10,15-18]$ - peritoneal dialysis in particular, but also home haemodialysis and minimal care haemodialysis. Incomplete presentation of treatment options may be a major reason for the under-utilisation of home dialysis therapies and contribute to delayed access to 
transplantation [17]. Pre-dialysis education may also influence employment status. People who had undergone pre-dialysis education were more likely to continue in work $[19,20]$. Finally, pre-dialysis education may also have a beneficial effect on both short-term [21] and longterm [14] survival. The risk of death in patients who did not receive pre-dialysis education has been estimated as double that in those who had received this education, and similar to that in late referrals [11].

A number of factors highlight the need for individualisation in pre-dialysis patient education. The prevalence of cognitive impairment increases with advancing renal failure independently of age and other confounding factors [22]. Twenty percent of patients referred to a pre-dialysis clinic [23] were cognitively impaired. The prevalence is higher in dialysis patients, particularly those on haemodialysis, fluctuates during the haemodialysis cycle, but tends to remain more stable in those on peritoneal dialysis $[24,25]$. Older pre-dialysis patients have a significantly reduced understanding of their illness [7]. Anaemia impairs cognitive function which treatment with erythropoiesis stimulating agents may improve [26]. These and other factors have clear implications for patients' ability to learn, and educational programmes should be tailored accordingly. Patients referred late for dialysis are less likely to receive many potentially helpful interventions than patients referred earlier [27]. These include pre-dialysis education. Such omissions can adversely affect outcomes. Patients referred late for dialysis should receive post-dialysis education to lessen the adverse effects of this omission and ensure they are also given the choice to move onto selfcare therapies rather than automatically remaining on their initial therapy. Patients whose pre-dialysis training was more than 6 months before they moved onto dialysis should be offered refresher training. Once on dialysis, patients will have a greater understanding of what it means and may be encouraged by this knowledge to move on to self-care therapies.

Other factors are important. Achieving education goals and adherence to the demands of the treatment can be compromised if patients have not accepted the severity and the chronicity of their condition. In addition, people learn more effectively when information is presented in a manner which accords with their own learning style and preferences. Learning style is a description of the attitudes and behaviours which determine an individual's preferred way of learning [28]. Learning preferences refers to the method of teaching that people prefer [29]. Learning styles can be classified into at least 4 categories [30], with any particular group likely to contain people with a mixture of learning styles. Rather than attempt categorisation of individuals, it may be more helpful to use a range of teaching methods within one session in order to allow learning to take place whatever the learning style.

Though long-term benefits of pre-dialysis education have been demonstrated [14], other benefits may be short lived [8]. Participants in a pre-dialysis patient education programme, showed better functional and emotional well-being than the non-educated comparison group during the first 6 months of initiating dialysis treatment after which the differences reduced, suggesting that education should be ongoing [8]. Studies of educational interventions in dialysis patients though are also limited. A recent systematic review of randomised control studies in this setting found 6 short-term, 13 medium-term and one long-term study, many of which were criticised as being of poor quality [31].

The studies mainly focussed on adherence to dietary and fluid management regimens, and some benefits of the interventions were observed. The need for good quality randomised controlled trials was emphasised.

\section{References}

1 Department of Health. The NHS Constitution. http://www.nhs.uk/ aboutNHS/constitution/Pages/Constitution.aspx. 2009

-2 Ghossein C, Serrano A, Rammohan M, et al. The role of comprehensive renal clinic in chronic kidney disease stabilization and management: The Northwestern experience. Semin Nephrol 2002;22:526-532

- 3 Levin A, Lewis M, Mortiboy P, et al. Multidisciplinary predialysis programs: quantification and limitations of their impact on patient outcomes in two Canadian settings. Am J Kidney Dis 1997;29:533-540

4 Department of Health. The Expert Patient Programme. http://www.dh. gov.uk/en/Aboutus/MinistersandDepartmentLeaders/

ChiefMedicalOfficer/ProgressonPolicy/ProgressrowsaleDocument/ DH_4102757. 2007. Department of Health
-5 Binik YM, Devins GM, Barre PE, et al. Live and learn: patient education delays the need to initiate renal replacement therapy in end-stage renal disease. J Nerv Ment Dis 1993;181:371-376

6 Devins GM, Paul LC, Barre PE, et al. Convergence of health ratings across nephrologists, nurses, and patients with end-stage renal disease. J Clin Epidemiol 2003;56:326-331

7 Gomez CG, Valido P, Celadilla O, et al. Validity of a standard information protocol provided to end-stage renal disease patients and its effect on treatment selection. Perit Dial Int 1999;19:471-477

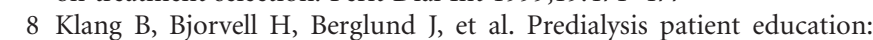
effects on functioning and well-being in uraemic patients. J Adv Nurs $1998 ; 28: 36-44$ 
$\checkmark 9$ Buck J, Baker R, Cannaby AM, et al. Why do patients known to renal services still undergo urgent dialysis initiation? A cross-sectional survey. Nephrol Dial Transplant 2007;22:3240-3245

10 Marron B, Ortiz A, de Sequera P, et al. Impact of end-stage renal disease care in planned dialysis start and type of renal replacement therapy - a Spanish multicentre experience. Nephrol Dial Transplant 2006;21 Suppl 2:ii51-ii55

11 Ravani P, Marinangeli G, Stacchiotti L, et al. Structured pre-dialysis programs: more than just timely referral? J Nephrol 2003;16:862-869

12 Inaguma D, Tatematsu M, Shinjo $\mathrm{H}$, et al. Effect of an educational program on the predialysis period for patients with chronic renal failure. Clin Exp Nephrol 2006;10:274-278

13 Devins GM, Mendelssohn DC, Barre PE, et al. Predialysis psychoeducational intervention and coping styles influence time to dialysis in chronic kidney disease. Am J Kidney Dis 2003;42:693-703

14 Devins GM, Mendelssohn DC, Barre PE, et al. Predialysis psychoeducational intervention extends survival in CKD: a 20-year follow-up. Am J Kidney Dis 2005;46:1088-1098

15 Manns BJ, Taub K, Vanderstraeten C, et al. The impact of education on chronic kidney disease patients' plans to initiate dialysis with self-care dialysis: a randomized trial. Kidney Int 2005;68:1777-1783

16 Little J, Irwin A, Marshall T, et al. Predicting a patient's choice of dialysis modality: experience in a United Kingdom renal department. Am J Kidney Dis 2001;37:981-986

17 Mehrotra R, Marsh D, Vonesh E, et al. Patient education and access of ESRD patients to renal replacement therapies beyond in-center hemodialysis. Kidney Int 2005;68:378-390

$\checkmark 18$ Goovaerts T, Jadoul M, Goffin E. Influence of a pre-dialysis education programme (PDEP) on the mode of renal replacement therapy. Nephrol Dial Transplant 2005;20:1842-1847

19 Rasgon S, Schwankovsky L, James-Rogers A, et al. An intervention for employment maintenance among blue-collar workers with end-stage renal disease. Am J Kidney Dis 1993;22:403-412
20 Rasgon SA, Chemleski BL, Ho S, et al. Benefits of a multidisciplinary predialysis program in maintaining employment among patients on home dialysis. Adv Perit Dial 1996;12:132-135

21 Ravani P, Marinangeli G, Tancredi M, et al. Multidisciplinary chronic kidney disease management improves survival on dialysis. J Nephrol 2003;16:870-877

22 Kurella TM, Wadley V, Yaffe K, et al. Kidney function and cognitive impairment in US adults: the Reasons for Geographic and Racial Differences in Stroke (REGARDS) Study. Am J Kidney Dis 2008;52:227-234

23 Nulsen RS, Yaqoob MM, Mahon A, et al. Prevalence of cognitive impairment in patients attending pre-dialysis clinic. J Ren Care 2008;34:121-126

24 Murray AM, Tupper DE, Knopman DS, et al. Cognitive impairment in hemodialysis patients is common. Neurology 2006;67:216-223

25 Williams MA, Sklar AH, Burright RG, et al. Temporal effects of dialysis on cognitive functioning in patients with ESRD. Am J Kidney Dis 2004;43:705-711

26 Marsh JT, Brown WS, Wolcott D, et al. rHuEPO treatment improves brain and cognitive function of anemic dialysis patients. Kidney Int 1991;39:155-163

27 Roderick P, Jones C, Drey N, et al. Late referral for end-stage renal disease: a region-wide survey in the south west of England. Nephrol Dial Transplant 2002;17:1252-1259

28 Honey P, Mumford A. The manual of learning styles. Peter Honey Publications, Maidenhead, Berkshire, UK: 1992

29 Cassidy S. Learning Styles: An overview of theories, models, and measures. Educational Psychology 2004;24:419-444

30 Kolb DA. The learning styles inventory: Technical Manual. Boston: McBer \& Company., 1985

31 Mason J, Khunti K, Stone M, et al. Educational interventions in kidney disease care: a systematic review of randomised trials. Am J Kidney Dis 2008;51:933-951 


\section{Planning, Initiating and Withdrawal of RRT} (Guidelines 5.1-5.6)

\section{Guideline 5.1 - RRT: Initiating renal replacement therapy}

We recommend that patients known to nephrology services for 3 months or more and who are planned to have renal support should start renal replacement therapy in a controlled manner, without the need for hospital admission and using an established access (arteriovenous fistula $[\mathrm{AVF}]$, arteriovenous $[\mathrm{AV}] \mathrm{graft}$, PD catheter) or by pre-emptive renal transplantation. (1B)

\section{Guideline 5.2 - RRT: Initiating renal replacement therapy}

We recommend that the decision to start RRT in patients with CKD stage $5\left(e G F R<15 \mathrm{ml} / \mathrm{min} / 1.73 \mathrm{~m}^{2}\right)$ should be based on a careful discussion with the patient of the risks and benefits of RRT taking into account the patient's symptoms and signs of renal failure, nutritional status, co-morbidity, functional status, and the physical, psychological and social consequences of starting dialysis in that individual. (1D)

\section{Guideline 5.3 - RRT: Initiating renal replacement therapy}

We suggest that serious consideration should be given to starting renal replacement therapy in patients with an eGFR $<6 \mathrm{ml} / \mathrm{min} / 1.73 \mathrm{~m}^{2}$, even if the patient is asymptomatic. (2C)

\section{Guideline 5.4 - RRT: Initiating renal replacement therapy}

We recommend that once a decision has been made to start dialysis in a patient with established access there should be no delay in starting treatment i.e. no waiting list to start dialysis. (1D)

\section{Guideline 5.5 - RRT: Initiating renal replacement therapy}

We recommend that urgent dialysis via a haemodialysis catheter should only be initiated where there is a clear clinical indication. (1D)

\section{Guideline 5.6 - RRT: Initiating renal replacement therapy}

We suggest that where dialysis is started via an established access (vascular or peritoneal) which fails to work effectively urgent corrective action should be taken and dialysis via a haemodialysis catheter avoided if possible. (2D)

\section{Audit measures 11-14}

Proportion of incident patients known to nephrology services for 3 months or more prior to initiation (planned initiation)

Proportion of planned initiations with established access or pre-emptive transplantation

Inpatient/outpatient status of planned initiations

Mean eGFR at start of renal replacement therapy

\section{Rationale for 5.1-5.6}

There are no criteria based on definitive evidence to advise when to start dialysis. Patients vary greatly in the symptoms they experience at similar levels of renal function as judged by eGFR. Even when eGFR is relatively well preserved, most nephrologists would agree that the failure of medical therapy to control or prevent severe fluid overload, persistent severe hyperkalaemia, marked acidosis, or poor nutrition leading to progressive loss of flesh-weight, would justify starting dialysis initiation. Nutritional status and dietary protein intake decrease progressively as renal function declines and this may become an important reason to initiate dialysis assuming other causes of poor nutrition have been excluded [1]. Over the last 10-20 years there has been a trend to starting dialysis at higher eGFR in the belief that earlier start dialysis will lead to better outcomes. UK Renal Registry data demonstrates that the mean eGFR at dialysis initiation has increased in a linear fashion from 6.2 to $8.4 \mathrm{ml} / \mathrm{min} / 1.73 \mathrm{~m}^{2}$ between 1997 and 2006 [2] However, there is no consistent correlation between eGFR at initiation and outcome [3]. Recent studies have demonstrated that age and co-morbidity $[2,4,5]$ appear to influence the starting eGFR presumably because advanced age and co-morbid problems render patients more symptomatic at a higher eGFR. Studies from the Netherlands and Scotland comparing patients who started dialysis at two different levels of residual renal function have shown no survival advantage after adjustments were made for lead time bias in the group of patients starting dialysis earlier [6-9]. In the multicentre prospective Netherlands study, 94 of the 253 incident patients began dialysis later than recommended in the US NKF KDOQI guideline and the adjusted benefit in survival after 3 years on dialysis was 2.5 months in the timely starter group [7]. This benefit may be attributed to lead time bias since the average delay in initiation of dialysis in the late starter 
group was 4.1 months. A randomised prospective study to compare 3 year morbidity and mortality after initiating dialysis when patients have a Cockcroft and Gault eGFR of $10-14 \mathrm{ml} / \mathrm{min} / 1.73 \mathrm{~m}^{2}$ or $5-7 \mathrm{ml} / \mathrm{min} /$ $1.73 \mathrm{~m}^{2}$ is underway (IDEAL study) [10].

Therefore, in the absence of clear evidence to guide when to start dialysis, this must be decided in discussion with the patient taking into account the patient's symptoms and signs and the biochemical disturbances weighed against the risks and inconveniences of starting dialysis. These guidelines are consistent with the European Best Practice Guidelines which recommend that renal replacement therapy should commence when a patient with an eGFR $<15 \mathrm{ml} / \mathrm{min} / 1.73 \mathrm{~m}^{2}$ has symptoms or signs of uraemia, fluid overload or malnutrition in spite of medical therapy or before eGFR has fallen below $6 \mathrm{ml} / \mathrm{min} / 1.73 \mathrm{~m}^{2}$ in an asymptomatic patient [11].

During the 1990's, the use of urea kinetics and creatinine clearance to define the goals for dialysis adequacy was extended to pre-dialysis patients as a guide to deciding when to start dialysis $[12,13]$. Many patients with advanced kidney failure not yet on dialysis had a lower Kt/V or creatinine clearance than had been defined as goals for patients on RRT. The concept of incremental dialysis was introduced by some [14] to describe the gradual increase in the dose of haemodialysis or peritoneal dialysis aiming to keep the sum of residual renal function and dialysis dose above the recommended target. Often this meant patients starting dialysis earlier than they had in the past and this has led to a gradual increase in the mean eGFR at start of dialysis (see above). Some have advocated that peritoneal dialysis may be used in this way to preserve residual renal function longer but definitive data is lacking [15]. There have been no controlled studies to support this approach in improving outcomes.

However, one benefit of starting dialysis in this manner is to allow for problems with vascular or peritoneal access. If the patients is started with a relatively higher eGFR and has problems with their arteriovenous fistula or graft, the fistula may be rested or undergo intervention (angioplasty/surgical revision) rather than resort to placement of a haemodialysis catheter. Similarly, problems with peritoneal dialysis catheters may be avoided by initial use of low volume exchanges which may reduce the incidence of leaks. Where problems do occur, catheter manipulation or replacement may be done without having to resort to temporary haemodialysis.

\section{References}

1 Ikizler TA, Greene JH, Wingarde RL, et al. Spontaneous dietary protein intake during progression of chronic renal failure. J Am Soc Nephrol 1995;6:1386-1391

2 Ansell D, Feehally J, Feest TG, et al. UK Renal Registry Report 2007, UK Renal Registry, Bristol, UK

-3 Roubicek C, Brunet P, Huiart L, et al. Timing of nephrology referral: Influence on mortality and morbidity. Am J Kidney Dis 2000;36:35-41

$\checkmark 4$ Kazmi WH, Gilbertson DT, Obrador GT, et al. Effect of co-morbidity on the increased mortality associated with early initiation of dialysis. Am J Kidney Dis 2005;46:887-896

5 Wilson B, Harwood L, Locking-Cusolito H, et al. Optimal timing of initiation of chronic hemodialysis? Hemodialysis Int 2007;11:263-269

-6 Traynor JP, Simpson K, Geddes CC, et al. Early initiation of dialysis fails to prolong survival in patients in end-stage renal failure. J Am Soc Nephrol 2002;13:2125-2132

7 Korevaar JC, Jansen MA, Dekker FW, et al. When to initiate dialysis: effect of proposed US guidelines on survival. Lancet 2001;358:1046-1050

8 Korevaar JC, Dekker FW, Krediet RT. Initiation of dialysis: is the problem solved by NECOSAD? Nephrol Dial Transplant 2003;18:1228-1229
9 Termorshuizen F, Korevaar JC, Dekker FW, et al. Time trends in initiation and dose of dialysis in end-stage renal disease patients in The Netherlands. Nephrol Dial Transplant 2003;18:552-558

10 Cooper BA, Branley P, Bulfone L, et al. The initiating dialysis early and late(IDEAL) study: study rationale and design. Perit Dial Int 2004;24:176-181

11 European Best Practice Guidelines. 2 The initiation of dialysis. Nephrol Dial Transplant 2005;20 [Suppl 9]: ix3-ix7

12 Tattersall J, Greenwood R, Farrington K. Urea kinetics and when to commence dialysis. Am J Nephrology 1995;15:283-289

13 Keshaviah PR, Emerson PF, Nolph KD. Timely initiation of dialysis. A urea kinetic approach. Am J Kidney Dis 1999;33:344-348

14 Burkart JM, Golper TA. Should we treat patients with incremental dialysis prescriptions? Blood Purif 2000;18:298-303

15 Pollock CA, Cooper BA, Harris DC. Early start peritoneal dialysis. Advances in Chronic Kidney Disease, 2007;14: e27-e34 


\section{Planning, Initiating and Withdrawal of RRT \\ (Guidelines 6.1-6.5)}

\section{Guideline 6.1 - RRT: End of life care: Conservative kidney management and withdrawal of dialysis}

\section{Conservative kidney care:}

We recommend that patients with advanced kidney disease (CKD stage 4 and 5) who, having opted not to dialyse, undergo conservative kidney management and those patients who have imminent or immediate endof-life care needs should be identified and their care prioritised. (1C)

\section{Guideline 6.2 - RRT: End of life care: Conservative kidney management and withdrawal of dialysis}

\section{Patients deteriorating despite dialysis:}

We recommend that patients who are struggling to cope on long-term dialysis as a result of progressive deterioration of underlying, irreversible, clinical problems, or sudden onset of a catastrophic clinical event, such as a stroke, should be recognised as being in imminent or immediate need of end-of-life care. (1C)

\section{Guideline 6.3 - RRT: End of life care: Conservative kidney management and withdrawal of dialysis}

\section{Advance care planning:}

We recommend that patients with a recognised need for end-of-life care, including those undergoing conservative kidney care and those deteriorating despite dialysis, should have an Advance Care Plan. (1C)

\section{Guideline 6.4 - RRT: End of life care: Conservative kidney management and withdrawal of dialysis}

\section{Dialysis withdrawal:}

We recommend that any decision to discontinue dialysis should be made within the context of ongoing end-of-life care planning. It should be made jointly by the patient and the responsible nephrologist in full consultation with relatives and carers, the family practitioner and members of the caring team. An assessment of competence should be carried out. Depression may need to be formally excluded. (1C)

Planning, Initiating and Withdrawal of Renal Replacement Therapy
Guideline 6.5 - RRT: End of life care:

Conservative kidney management and withdrawal of dialysis

Care in the last days:

We recommend that in the last days of life there should be good symptom relief, psychological, spiritual and culturally sensitive care for the dying patient and their family, (whether at home, in a hospice or a hospital setting) followed by the provision of culturally appropriate bereavement support. (1C)

\section{Audit measures 15-20}

Units should have a register of patients with End of Life Care needs, including those undergoing conservative kidney management, those deteriorating despite dialysis, and those withdrawing from dialysis. The register should link with primary care End of Life Registers

The number of patients with stage $5 \mathrm{CKD}$ who are undergoing conservative kidney management as a proportion of all patients with stage $5 \mathrm{CKD}$

The number of patients withdrawing from dialysis as a proportion of all deaths on dialysis

The proportion of those patients identified as having End of Life Care needs who have a workable Advance Care Plan, which includes details of the nominated renal Key-Worker, patient preferences and choices with respect to priorities of care, and details of the individual needs of carers

The proportion of all expected in-patient deaths in which the Integrated (Liverpool) Care Pathway for care of the dying has been utilised

Units should participate in National End of Life Care audits such as the Liverpool Care Pathway: National care of the dying audit - hospitals

\section{Rationale for 6.1-6.5}

The prevalence of advanced kidney disease increases dramatically with age. Some elderly patients with this condition are frail, and dependent, with multiple extrarenal co-morbidities. Dialysis in these circumstances adds to the burdens imposed by these conditions, and in high-risk patients, may not extend life $[1,2]$. Octogenarians who were dialysed, survived longer than those not offered dialysis, though the latter were more dependent, more socially excluded, more had been referred late, and more were diabetic [3]. Choosing not to commence dialysis in favour of a more conservative approach is an option for some patients, most of whom are elderly, frail and dependent [1]. The conservative approach aims

Nephron Clin Pract 2011;118(suppl 1):c189-c208 
to provide all aspects of clinical care, with the exception of dialysis, including the use of erythropoiesis stimulating agents to manage anaemia, together with ongoing support by the multidisciplinary team in liaison with community and palliative care services. Quality of life for patients following a conservative pathway appears to be comparable to that in haemodialysis patients, though data are very limited [4].

At the start of dialysis the median age of UK patients is over 65 years [5]. Twenty percent have diabetes mellitus, more than $50 \%$ have one or more other co-morbidity and over a third are significantly dependent $[6,7]$. A small proportion has dementia and in this group survival is poor [8]. Furthermore, dialysis is inefficient, tending to maintain patients in a persistently uraemic state, and invasive, with a significant short- and mediumterm complication rate. As a result patients on dialysis have a high morbidity and mortality compared with non-uraemic age-matched peers, with a median survival worse than many cancers. The expected remaining life years of a dialysis patient aged 65-69 years is 3.9 years compared with 17.2 years for an aged matched person in the general population [9]. With increasing age and dependency, progression of underlying medical conditions, or the emergence of new medical problems, life on dialysis may become difficult to bear. In such situations, it is important to recognise that end of life may be approaching, signalling the need to re-focus the emphasis of care, from prolongation of life, to relief of symptoms, maintenance of comfort and attention to psychological, social and spiritual concerns. There are other triggers [10] for the need for a supportive or palliative approach including substantial weight loss and severe hypoalbuminaemia, and the use of the 'surprise' question: 'Would you be surprised if your patient were to die in next 6-12 months?. This may elicit a negative response for a substantial proportion of dialysis patients [11].

Starting the conversation with patients and carers requires judgement, sensitivity and good communication. A shared view, between patient, family and carers, and all members of the multidisciplinary team, with respect to the patient's current situation and likely prognosis, is key, though may take time to achieve. Patients differ in their need for information and involvement. Planning should acknowledge this. Advance Care Planning facilitates communication between patients, families, health care professionals, and others, about the patient's wishes for end-of-life care [12]. Offering timely, appropriate, individualised information enhances rather than diminishes hope [13]. The plan should emphasise patients' preferences and choices, and include details of the nominated Key-Worker [14]. It should also document the outcomes of on-going assessments and multidisciplinary team meetings, detail communications with primary care and palliative care services, refer to the individual needs of carers, and link with other End-of-Life tools, notably the Gold Framework [10], and the Preferred Priorities of Care document [15]. Some patients deteriorating despite dialysis will choose to withdraw from treatment. Some will choose to continue, perhaps with reduced sessional frequency and/or duration. For these patients the plan should address the circumstances under which the patient would find continued treatment, including resuscitation, unacceptable.

Withdrawal from dialysis is now a common mode of death in the dialysis populations of the US $[16,17]$, the UK [18] and in other developed countries [19]. Most studies are retrospective; there is little prospective data [20]. Withdrawal is more frequent in the elderly [20, 21 , in those with chronic or progressive co-morbid disease $[20,22]$ and in those with increased dependency $[18,20]-$ all features which increasingly characterise the growing prevalent dialysis population. In most cases withdrawal occurs in the context of increasing dependency associated with progressive clinical decline or a severe acute clinical event. A small proportion of patients though, withdraw in the absence of such imperatives. In a UK study, $15 \%$ of withdrawals were apparently in this category [18]. The issue of withdrawal may be raised by the physician, the dialysis staff, the patient or the family $[16,18,19]$. An assessment of competence to decide is important, many studies report a high proportion of patients as not competent $[16,18]$. Depression may be a factor [23] but 'probably does not play a major role in most patients' decisions on withdrawal, though may be important in individuals' [24]. Nevertheless it is important to exclude potentially treatable depression especially in patients contemplating withdrawal in the absence of significant co-morbidity or dependency. There are sufficient differences between the risk factor profiles for withdrawal and those for suicide in this population, to suggest that these are 'diverging outcomes rather than a continuum of a similar underlying process' [25].

A number of studies have attempted to define quality end-of-life care from the patient's perspective. Qualitative interviewing of patients many of whom were on dialysis identified 5 domains; receiving adequate pain and symptom management, avoiding inappropriate prolongation of dying, achieving a sense of control, relieving the perceived burden on loved ones, and 
strengthening relationships with loved ones [26]. Similar themes have emerged from other studies [27, 28]. These provide a focus for improving the quality of care of the dying. Use of the Integrated (Liverpool) Care Pathway and the supplementary guidelines for prescribing in advanced kidney disease may facilitate good quality care in this setting $[29,30]$. With good quality care of the dying most patients withdrawing from dialysis may experience 'good deaths' [31].

\section{References}

1 Smith C, Da Silva-Gane M, Chandna S, et al. Choosing not to dialyse: evaluation of planned non-dialytic management in a cohort of patients with end-stage renal failure. Nephron Clin Pract 2003;95:c40-c46

-2 Murtagh FE, Marsh JE, Donohoe P, et al. Dialysis or not? A comparative survival study of patients over 75 years with chronic kidney disease stage 5. Nephrol Dial Transplant 2007;22:1955-1962

$\checkmark 3$ Joly D, Anglicheau D, Alberti C et al. Octogenarians reaching end-stage renal disease: cohort study of decision-making and clinical outcomes. J Am Soc Nephrol 2003;14:1012-1021

$\checkmark 4$ De Biase V, Tobaldini O, Boaretti C et al. Prolonged conservative treatment for frail elderly patients with end-stage renal disease: the Verona experience. Nephrol Dial Transplant 2008;23:1313-1317

5 Farrington K, Rao R, Gilg J, et al. New adult patients starting renal replacement therapy in the UK in 2005 (chapter 3). Nephrol Dial Transplant 2007;22(Suppl 7):vii11-vii29

6 Tomson C, Udayaraj U, Gilg J, et al. Comorbidities in UK patients at the start of renal replacement therapy (chapter 6). Nephrol Dial Transplant 2007;22(Suppl 7):vii58-vii68

7 Chandna SM, Schulz J, Lawrence C, et al. Is there a rationale for rationing chronic dialysis? A hospital based cohort study of factors affecting survival and morbidity. BMJ 1999;318:217-223

$>8$ Rakowski DA, Caillard S, Agodoa LY, et al. Dementia as a predictor of mortality in dialysis patients. Clin J Am Soc Nephrol 2006;1:1000-1005

9 United States Renal Data Systems Annual Data Report. http://www. usrds.org/2008/pdf/V2_02_.pdf. 2008

10 NHS End of LIfe Care Programme. Gold Standards Framework. http:// www.goldstandardsframework.nhs.uk/gp_contract.php. 2006

11 Moss AH, Ganjoo J, Sharma S et al. Utility of the 'surprise' question to identify dialysis patients with high mortality. Clin J Am Soc Nephrol 2008;3:1379-1384

$\checkmark 12$ Holley JL. Palliative care in end-stage renal disease: focus on advance care planning, hospice referral, and bereavement. Semin Dial 2005;18: 154-156

13 Davison SN, Simpson C. Hope and advance care planning in patients with end stage renal disease: qualitative interview study. BMJ 2006;333:886

14 Department of Health. End of Life Strategy. 2008

15 Preferred Priorities for Care. http://www.endoflifecareforadults.nhs.uk/ eolc/CS310.htm. 2007

-16 Neu S, Kjellstrand CM. Stopping long-term dialysis. An empirical study of withdrawal of life-supporting treatment. N Engl J Med 1986;314:14-20
17 Mailloux LU, Bellucci AG, Napolitano B, et al. Death by withdrawal from dialysis: a 20-year clinical experience. J Am Soc Nephrol 1993;3: 1631-1637

18 Catalano C, Goodship TH, Graham KA, et al. Withdrawal of renal replacement therapy in Newcastle upon Tyne: 1964-1993. Nephrol Dial Transplant 1996;11:133-139

19 Murtagh F, Cohen LM, Germain MJ. Dialysis discontinuation: quo vadis? Adv Chronic Kidney Dis 2007;14:379-401

20 Bajwa K, Szabo E, Kjellstrand CM. A prospective study of risk factors and decision making in discontinuation of dialysis. Arch Intern Med 1996;156:2571-2577

21 Munshi SK, Vijayakumar N, Taub NA, et al. Outcome of renal replacement therapy in the very elderly. Nephrol Dial Transplant 2001;16:128-133

22 Leggat JE, Jr., Bloembergen WE, Levine G, et al. An analysis of risk factors for withdrawal from dialysis before death. J Am Soc Nephrol 1997;8:1755-1763

23 McDade-Montez EA, Christensen AJ, Cvengros JA, et al. The role of depression symptoms in dialysis withdrawal. Health Psychol 2006;25:198-204

24 Cohen LM, Germain MJ. The psychiatric landscape of withdrawal. Semin Dial 2005;18:147-153

25 Kurella M, Kimmel PL, Young BS, et al. Suicide in the United States end-stage renal disease program. J Am Soc Nephrol 2005;16:774-781

26 Singer PA, Martin DK, Kelner M. Quality end-of-life care: patients' perspectives. JAMA 1999;281:163-168

27 Steinhauser KE, Clipp EC, McNeilly M, et al. In search of a good death: observations of patients, families, and providers. Ann Intern Med 2000;132:825-832

28 Patrick DL, Engelberg RA, Curtis JR. Evaluating the quality of dying and death. J Pain Symptom Manage 2001;22:717-726

29 The Marie Curie Palliative Care Institute Liverpool. The Liverpool Care Pathway for the dying patient. http://www.mcpcil.org.uk/liverpool_ care_pathway. 2008

30 DH Renal NSF team and Marie Curie Palliative Care Institute. DH Renal NSF team and Marie Curie Palliative Care Institute. Guidelines for Liverpool Care Pathway prescribing in advanced kidney disease. 2008

31 Cohen LM, Germain MJ, Poppel DM, et al. Dying well after discontinuing the life-support treatment of dialysis. Arch Intern Med 2000;160: 2513-2518 


\section{Acknowledgements}

The authors would like to thank and acknowledge the contribution of Natasha Baron who helped carry out the literature review.

The authors also thank Fiona Loud for reviewing and commenting on the draft version of this clinical practice guideline.
Declarations of interest

Dr Warwick has received sponsorship to attend scientific meetings from Roche and Ortho-Biotech and has no shares or retainers. Professor Farrington has no conflicts of interest to declare. 